\title{
Identifying and Treating Ascending Cholangitis: A case report and review of literature.
}

\author{
Phillip Lindholm ${ }^{1}$, Patrick Young ${ }^{1 *}$, Walter Reed ${ }^{2}$
}

Received: 04 May 2018; Accepted: 30 June 2018; Published online: 20 July 2018

DOI: https://doi.org/10.32391/ajtes.v2i2.10

\begin{abstract}
Acute cholangitis is an infection of the biliary system that typically results from obstruction. Common causes include choledocholithiasis, strictures, foreign bodies (such as biliary stents) parasitic worms (e.g. ascarids) and compression from an external structure. Obstruction allows for higher bacterial concentrations and bacterial proliferation. With biliary stasis and increases in intraductal pressure, bacteria migrate into the venous and lymphatic systems with subsequent bacteremia. The rate of gallstone development is 3-4 \% annually in those $>60$ years old with up to a $15 \%$ overall prevalence in the US. In the US, $85 \%$ of ascending cholangitis cases are a consequence of choledocholithiasis. The gram-negative bacteria E coli, Klebsiella, Pseudomonas and Enterobacter are the most commonly identified pathogens. Anaerobes are less common.

Ascending cholangitis is classically diagnosed by the presence of Charcot's triad - fever, right upper quadrant pain and jaundice. Though very specific, the presence of Charcot's triad is only $26 \%$ sensitive and thus its absence does not rule out the diagnosis. All patients with suspected ascending cholangitis should undergo appropriate fluid resuscitation, be given broad spectrum antibiotics to cover the likely enteric pathogens, and closely monitored for worsening in their clinical condition.

Once initial assessment is complete and resuscitative efforts begun, imaging is often helpful in confirming the diagnosis of ascending cholangitis. After the diagnosis has been confirmed, ERCP and biliary drainage is indicated.
\end{abstract}

Keywords: Ascending cholangitis, treatment, diagnosis

*Corresponding author; Patrick E. Young

$\equiv$ Email: peyoungmd@gmail.com

${ }^{1}$ Uniformed Services University of the Health Sciences, F. Edward Heberrt School of School, USA

${ }^{2}$ National Military Medical Center, Department of Medicine, Gastroenterology Service, USA 


\section{Introduction}

Case Example/; A 48-year-old man with one prior episode of gallstone pancreatitis and subsequent cholecystectomy presented to a community hospital Emergency Room complaining of one day of progressive epigastric pain with bilious, nonbloody vomiting. The pain was non-radiating and not associated with fevers or obvious jaundice. Initially his heart rate was in the 80s and blood pressure $120 \mathrm{~s} / 80 \mathrm{~s}$. His WBCs on admission were $7300 / \mathrm{uL}$, his total bilirubin was $2.3 \mathrm{mg} / \mathrm{dL}, \mathrm{AST} / \mathrm{ALT}$ were 516/388 U/L, GGT $335 \mathrm{U} / \mathrm{L}$ and his alkaline phosphatase was $130 \mathrm{U} / \mathrm{L}$. His lipase was normal at $49 \mathrm{U} / \mathrm{L}$. CT abdomen/pelvis with contrast was performed and the initial review suggested possible, though not obvious, biliary pathology. $\mathrm{He}$ was admitted for observation.

Though our patient had a relatively benign initial presentation, he developed a fever to 101.9 degrees Fahrenheit on his first day of admission. A repeat review of his $\mathrm{CT}$ scan at our facility suggested a $4 \mathrm{~mm}$ filling defect in the common bile duct suspicious for CBD stone. Piperacillintazobactam and IV fluids were given and the patient quickly defervesced though his bilirubin increased to $4.3 \mathrm{mg} / \mathrm{dL}$.

In cases such as this, it is important to rapidly determine (1) if the patient has ascending cholangitis and (2) how quickly intervention is required. In the article below, the authors discuss the approach to suspected ascending cholangitis including special situations including anticoagulation and pregnancy.

\section{Epidemiology}

Acute cholangitis is an infection of the biliary system that typically results from obstruction. Common causes include choledocholithiasis, strictures, foreign bodies (such as biliary stents) parasitic worms (e.g. ascarids) and compression from an external structure. Obstruction leads to increased pressure in the biliary tree and biliary stasis with subsequent malfunction of normal biliary defenses and increase in bacterial concentration. In health, there is typically minimal migration of duodenal bacteria past the ampulla in a patient with no prior biliary intervention. Bacteria which do migrate upstream are generally flushed back out via normal bile flow. Obstruction allows for higher bacterial concentrations and bacterial proliferation. With biliary stasis and increases in intraductalpressure, bacteria migrate into the venous and lymphatic systems with subsequent bacteremia [1]. Since normal flow of bile moves bacteria out of the biliary system to prevent infection, restoring a normal flow of bile is the cornerstoneof treatment.

The rate of gallstone development is 3-4 \% annually in those $>60$ years old with up to a $15 \%$ overall prevalence in the US. Multiparity, female gender, obesity, and certain ethnic backgrounds also predispose to cholelithiasis. Seventy-five percent of female Pima Indians, for example, have gallstonesas adults [2]. Migration of gallstones distally in the common bile duct may lead to ductal obstruction and cholangitis. In the US, $85 \%$ of ascending cholangitis cases are a consequence of choledocholithiasis [3]. Additional risk factors include primary sclerosing cholangitis, biliary stricture, and recurrent pyogenic cholangiopathy. Patients with prior biliary intervention such as biliary stent placement are at increased risk for cholangitis due tobiofilm formation and eventual stent obstruction [4]. Of patients admitted with gallstone disease, up to $9 \%$ are for acute (ascending) cholangitis. The gram-negative bacteria E coli,Klebsiella, Pseudomonas, and Enterobacter are 
the most commonly identified pathogens.

Anaerobes are less common.

\section{Diagnosis of Cholangitis}

Ascending cholangitis is classically diagnosed by the presence of Charcot's triad - fever, right upper quadrant pain and jaundice. Though very specific, the presence of Charcot's triad is only $26 \%$ sensitive and thus its absence does not rule out the diagnosis [5]. A high percentage of patients with acute cholecystitis will also present with positive Charcot's triad, meaning that it also lacks specificity. In severe cholangitis with sepsis, Reynold's pentad, which includes hypotension/shock and altered mental status in addition to the triad, is found in fewer than $7 \%$ of patients [6]. While it is vital to consider and exclude ascending cholangitis in such cases, it is also important to remember that a number of other conditions may lead to RUQ and jaundice, and that some of these conditions may be associated with fever as well. (table1)

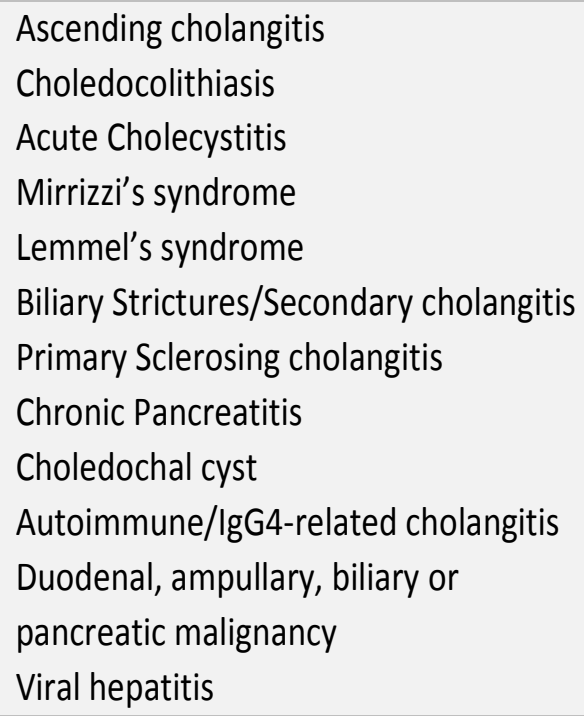

Table 1: Causes of right upper quadrant pain and jaundice.
A more clinically applicable tool for diagnosis may be the Tokyo guidelines [5]. These guidelines divide cases into suspected or definite based on three categories of criteria: systemic symptoms, laboratory results, and imaging findings. (Table 2) For suspected disease, one must have systemic symptoms as well as suggestive imaging or lab findings. Definitive diagnosis calls for systemic symptoms and both suggestive imaging and lab findings.

It is important to remember that in acute cholecystitis, a leukocytosis and mild bilirubinemia may be present, though bilirubin greater than 4 $\mathrm{mg} / \mathrm{dL}$ suggests common bile duct obstruction [7].A common bile duct measuring greater than $6 \mathrm{~mm}$ also suggest a mechanical biliary obstruction, though prior cholecystectomy may enlarge the common bile duct, creating a diagnostic dilemma. Acute viral hepatitis may also present with jaundice and RUQ pain, though significant elevations in WBCs and CRP are rare[4]. In such cases, imaging of the biliary system should be normal. Acute viral hepatitis serologies should be performed when transaminase elevation is present and there is no obvious biliary pathology. 


\begin{tabular}{|c|c|c|}
\hline$A$ & Fever or chills & SIRS \\
\hline$B$ & $\begin{array}{l}\text { Direct } \\
\text { hyperbilirubinemia }\end{array}$ & $\begin{array}{l}\text { Elevated } \\
\text { aminotransferases } \\
\text { (>1.5 ULN) }\end{array}$ \\
\hline$C$ & $\begin{array}{l}\text { Biliary ductal } \\
\text { dilation }\end{array}$ & $\begin{array}{l}\text { Definitive etiology } \\
\text { seen (e.g. biliary } \\
\text { stone) }\end{array}$ \\
\hline
\end{tabular}

Table 2: Tokyo diagnostic criteria for ascending cholangitis. ULN= upper limits of normal.

SIRS: Systemic Inflamatory Response Syndrome; $A$ : Systemic symptoms; $B$ : Lab. findings; $C$ : Imaging findings

\section{Management}

Initial steps should include a rapid assessment of clinical severity including vital signs as well as mental status. Basic laboratory evaluation is performed to assess for end organ dysfunction and to confirm etiology. These labs should include complete blood count, complete metabolic panel, and INR/PT. In those who are febrile, blood cultures should be performed prior to the initiation of antibiotics. In patients with SIRS or evidence of end organ dysfunction, admission to an intensive care unit is recommended.

All patients with suspected ascending cholangitis should undergo appropriate fluid resuscitation, be given broad spectrum antibiotics to cover the likely enteric pathogens, and closely monitored for worsening in their clinical condition. Risk stratification is imperative to determine the timing of interventions to decompress the biliary system such as ERCP or percutaneous drainage. The Revised Tokyo guidelines provide a three-tiered grading system for this purpose (table 3 ).

\section{Grade III: Cholangitis with dysfunction in at severe least one organ or system:}

1. Cardiovascular dysfunction: hypotension requiring pressor support

2. Neurological dysfunction: altered mental status

3. Respiratory dysfunction: $\mathrm{PaO}_{2} / \mathrm{FiO}_{2}$ ratio $<300$

4. Renal dysfunction: oliguria, serum creatinine $\mathbf{} \mathbf{2 . 0}$ $\mathrm{mg} / \mathrm{dl}$

5. Hepatic dysfunction: INR $>1.5$

6. Hematological dysfunction: platelets $<100,000 / \mathrm{mm}^{3}$

\begin{tabular}{|c|c|}
\hline $\begin{array}{l}\text { Grade II: } \\
\text { moderat } \\
\text { e }\end{array}$ & $\begin{array}{l}\text { Cholangitis with any two of the } \\
\text { following: } \\
\begin{aligned} \text { 1. Abnormal WBC count } \\
\left(>12,000 / \mathrm{mm}^{3} \text { or }\right. \\
\left.<4,000 / \mathrm{mm}^{3}\right) \\
\text { 2. High fever }\left(\geq 39^{\circ} \mathrm{C}\right) \\
\text { 3. Age }(\geq 75 \text { years old) } \\
\text { 4. Hyperbilirubinemia (total } \\
\text { bilirubin } \geq 5 \mathrm{mg} / \mathrm{dl}) \\
\text { 5. Hypoalbuminemia (<0.7 } \mathrm{x} \\
\text { lower limit of normal) }\end{aligned}\end{array}$ \\
\hline $\begin{array}{l}\text { Grade I: } \\
\text { mild }\end{array}$ & $\begin{array}{l}\text { Cholangitis that does not meet } \\
\text { criteria for moderate or severe } \\
\text { disease }\end{array}$ \\
\hline
\end{tabular}

Table 3: Revised Tokyo criteria for determining the severity of cholangitis.

Patients with severe disease should receive ERCP as soon as they are medically stabilized. All others can receive the procedure safely within 24 hours, though the exact timing is not certain [5].

Once initial assessment is complete and resuscitative efforts begun, imaging is often helpful in confirming the diagnosis of ascending cholangitis. 
Right upper quadrantultrasound (RUQUS)is often the first imaging study performed given its ease of access, low cost, and lack of radiation exposure. Biliary dilation on RUQUS is often seen, but its absence does not rule out cholangitis. In those in whom the diagnosis remains in doubt after RUQ US, MRCP is the best cross-sectional imaging modality to define a definitive etiology given its highresolution reconstruction of the biliary tree without contrast or radiation exposure. CT scan may also be used in those who are not candidates for MRCP or where MRCP is not readily available, though it has less sensitivity for choledocholiths which is the most common etiology. While ERCP is highly accurate as a diagnostic test, its higher risk profile makes is most appropriate as a therapeutic rather than a diagnostic tool.

Once the diagnosis has been confirmed, ERCP and biliary drainage is indicated. The timing of endoscopy depends on the severity as illness as discussed above. In those with category III(severe) disease, biliary drainage should be performed as soon as the patient has been stabilized. For those in the moderate and mild categories, the timing is less clear. The Tokyo guidelines suggest that the lowest severity patients can safely receive biliary drainage in 24 hours [8]. This is largely based on expert opinion as well as a study by Chak and colleagues which showed that delay beyond 24 hours was associated with worse outcomes [9]. This study, however, did not stratify subjects by severity and so it is possible that the results were confounded by a higher number of severely ill patients. Recent studies indicate that the safe window of ERCP may in fact be longer. Khashab and colleagues retrospectively examined 90 patients with ascending cholangitis treated with ERCP and drainage. They found that after 72 hours both total costs as well as the composite endpoint of death, persistent organ failure, and ICU days were higher [10]. Hou, et al. performed a somewhat larger study looking at the impact of ERCP timing on outcome in 199 patients. While no difference in mortality was found, delays of greater than 48 hours led to a disproportionate increase in length of stay and that at greater than 72 hours patients had more hypotension requiring vasopressor support [11]. One reason for delay in ERCP in some centers is the impression that cases done on the weekends may have worse outcomes than those done during the work week, presumably due to less experienced teams performing these procedures. Tabibian, et al. retrospectively examined this possibility, comparing outcomes in 181consecutive ERCP at the Mayo Clinic [12] There were no differences in any of the examined outcomes in ERCPs performed on the weekend versus weekdays. While highly quality prospective studies on the matter would be welcome, it appears that ERCP is equally safe and effective on the weekend, and that most ERCP for biliary decompression in mild to moderate cases should be done within 48 hours and certainly no later than 72 hours after admission. Of course, careful observation to detect clinical deterioration warranting earlier intervention is critical.

Given that ERCP can be delayed 24-48 hours in nonsevere cases responding to medical therapy, some consideration should be given to transferring patients to a center that performs a high volume of ERCP. When patients receive ERCP by endoscopists and at centers with high volume of ERCP, the likelihood of success increases and the likelihood of adverse events decreases significantly [13]. This principle must be balanced with the patients' wishes, clinical stability and regional availability of ERCP. 


\section{Special Situations:}

While ERCP with stent placement is a low-risk for bleeding complications per ASGE guidelines [14], sphincterotomy is high risk and the endoscopists must take caution in patients currently receiving anticoagulation or dual antiplatelet therapy. Bleeding occurs in up to $2 \%$ of sphincterotomies and the risk increases with anticoagulation, antiplatelet agents or acute inflammation [15]. For an elective high-risk procedure, warfarin would be stopped five days prior and the novel anticoagulants stopped at least 2 days prior depending upon creatinine clearance [14]. Aspirin can be continued peri-procedurally, though clopidogrel should be discontinued at least 7 days prior to sphincterotomy. Clearly, one does not have the luxury of such time in cases of acute cholangitis.

As such, the endoscopist has two choices - to reverse the effects of the anticoagulants/antiplatelet agents or to avoid or minimize the size of sphincterotomy. The precise manner of reversing these agents is beyond the scope of this article and the reader is directed to several excellent articles on the topic. (16) If a patient is in need of biliary drainage and the risk of reversal is deemed unacceptably high, one may avoid a sphincterotomy and a place a 7 -french plastic biliary stent. This stent is of sufficient size to effect adequate drainage in most cases, but small enough to be easily passed through an intact sphincter of Oddi. There is some data that avoiding sphincterotomy may decrease the risk of post-ERCP pancreatitis (PEP) as well [17]. If the endoscopist desires to remove a choledocholith at the same setting, this generally cannot be done via an intact papilla. Options in this case include making a small (2-3mm) sphincterotomy and performing a papillary balloon dilation. This is associated with fewer bleeding complications and the limited eliminates the increase risk of PEP induced by balloon dilation in western population[18]. If stone extraction is incomplete or not performed, follow up ERCP may be accomplished after clinical recovery from cholangitis, typically in 3-4 weeks.

Pregnancy is a unique clinical situation where risks to the unborn child must be weighed against the benefits of treatment. Pregnancy itself increases the risk for biliary stones [19]. Up to $10 \%$ of women post-partum have evidence of new cholelithiasis, though only $1 \%$ of those will develop symptoms. Pregnancy is also a risk factor for post-ERCP pancreatitis, occurring in $12-16 \%$ of patients; prophylaxis with indomethacin is restricted as this can be teratogenic. In addition, MRCP is contraindicated in the first trimester. Sedation, radiation, and the procedural risk of pancreatitis involved with ERCP can pose harm to both mother and child. Acute cholangitis, however, poses a higher risk to the patients and ERCP is therefore indicated even in pregnancy.(20)

According to the American College of Obstetricians and Gynecologists, radiation exposure of less than $50 \mathrm{mGy}$ has not been shown to be harmful to a fetus, and ERCP exposes a fetus to less than $6 \mathrm{mGy}$, though 'as low as reasonably achievable' should be the goal. If surface ultrasound fails to confirm biliary stones, EUS could be used provided the benefits were found to outweigh the risks of sedation. If there is strong clinical suspicion for cholangitis, ERCP can be attempted without fluoroscopy and several different approaches have been described. Wire placement can be confirmed, aspiration of bile through the sphincterotomy or balloon, or in rare instances, via cholangioscopy. Once successful biliary cannulation has been confirmed, a plastic biliary stent can be placed that 
will allow for appropriate bile drainage.

Alternatively, a sphincterotomy could be performed. Either of these options may result in spontaneous extraction of biliary stones; if stones remain, as long as biliary drainage occurs, removal can be attempted after delivery if late enough in pregnancy.

Sedation to the mother does pose risk to the child, and thus the ASGE recommends an Obstetrics consult prior to any procedure as well as the use of an anesthesiology providerfor the procedure itself [20]. There are currently no available medications that are class $A$, though meperidine and propofol areclass $B$; fentanyl and midazolam have not been shown to be teratogenic in humans at usual doses but are not preferred.

If ERCP is unsuccessful or unavailable, biliary drainage must be accomplished by other means. An interventional radiologist can perform percutaneous trans-hepatic biliary drainage under ultrasound guidance [5]. This is most likely to be successful when there is significant biliary dilation for the radiologist to target. A percutaneous drain placed this way can be temporizing until definitive removal of the obstruction can take place when the patient is more stable. Another option is the socalled rendezvous procedure where the interventional radiologist advances a percutaneously placed guidewire trans-hepatically into the duodenum [21]. The endoscopist then retrieves the wire and performs the remainder of the ERCP in standard fashion.

In patients with surgical altered anatomy such as those post-roux-en- $Y$ gastric bypass or pancreaticoduodenectomy (Whipple procedure), endoscopic access to the bile duct can be more challenging. Options in these cases include balloon- assisted enteroscopy, ERCP via surgically placed gastrostomy, EUS guided biliary access, and IRdirected transhepatic drainage [22]. Selection will be based on local expertise. If none of the aforementioned options were successful, surgical biliary drainage may be performed, though this is a much more morbid procedure, especially in a patient with severe cholangitis.

\section{Prognosis and follow up}

Prior to ERCP, mortality from severe cholangitis was nearly $50 \%$ [23], though modern data suggests mortality ranges from 3 - 11\% [24,25] with much of it coming from severe cases. If a plastic stent is placed, this needs to be removed within 8 weeks of placement as there is a high rate of stent occlusion if they are left in place longer with more narrow stents more likely to occlude [26]. In patients with an intact gallbladder in whom choledocholithiasis was the etiology of the cholangitis, cholecystectomy is recommended due to a significantly increased morbidity, often due to recurrent cholangitis, when surgery is foregone [27]. Due to the associated inflammation, most surgeons prefer a reasonable interval between the episode and subsequent cholecystectomy. Li and colleagues compared patients undergoing surgery within 6 weeks of $A C$ to those with a longer delay. Surgical delay was associated with significantly more intraoperative ( $28.8 \%$ vs $9.4 \%$ ) and postoperative (42.5\% vs $15.6 \%$ ) complications [28]. In those with cholangitis due to biliary strictures, ascertaining the etiology of the stricture through directed sampling by brushing, biopsies, and or EUS/FNA is critical, though this is often best performed after the resolution of the acute episode. 


\section{Case Example Conclusion}

ERCP was performed on hospital day 2 and revealed an $8 \mathrm{~mm}$ stone in the distal common bile duct. $A$ sphincterotomy was performed and a brown and black pigment stone was removed - likely a retained stone left in place during his cholecystectomy. Balloon sweep did not reveal any additional stones. PCR testing detected

Enterobacteriaceae and Escherichia coli in his blood, though standard blood cultures were negative, and the patient recovered uneventfully on a two-week course of oral ciprofloxacin

\section{References}

1. Ahmed M. Acute cholangitis - an update. World J GastrointestPathophysiol. 2018; 9: 1-7.

2. Knowler W.C., Carraher M.J., Pettitt D.J., Bennett P.H. (1984) Epidemiology of cholelithiasis in the Pima Indians. In: Capocaccia L., Ricci G., Angelico F., Angelico M., Attili A.F. (eds) Epidemiology and Prevention of Gallstone Disease. Springer, Dordrecht

3. Lillemoe KD. Surgical treatment of biliary tract infections. Am Surg. 2000; 66: 138-44.

4. Jensen $\mathrm{KH}$, JØrgensen $\mathrm{T}$. Incidence of gallstones in a Danish population. Gastroenterol. 1991; 100: 790-4.

5. Kiriyama S, Kozaka K, Takada T, Strasberg SM, Pitt HA, Gabata T, Hata J, Liau KH, Miura F, Horiguchi A, Liu KH, Su CH, Wada K, Jagannath $P$, Itoi T, Gouma DJ, Mori Y, Mukai S, Giménex ME, Huang WS, Kim MH, Okamoto K, Belli G, Dervenis C, Chan ACW, Lau WY, Endo I, Gomi H, Yoshida M, Mayumia T, Baron TH, de Santibañes E, Teoh AYB, Hwang TL, Ker CG, Chen MF, Han HS, Yoon YS, Choi IS, Yoon DS, Higuchi R, Kitano S, Inomata M, Deziel DJ, Jonas E, Hirata K, Sumiyama Y, Inui K, Yamamoto M.
Tokyo Guidelines 2018: diagnostic criteria and severity grading of acute cholangitis (with videoes). J Hepatobiliary Pancreat Sci. 2018; 25: 17-30.

6. Ramchandani, M. Pal P, Reddy DN. Dig Endosc. 2017; 29: 78-87.

7. ASGE Standards of Practice Committee, Maple JT, Ben-Menachem T, Anderson MA, Appalaneni V, Banerjee S, Cash BD, Fisher L, Harrison ME, Fanelli RD, Fukami N, Ikenberry SO, Jain R, Khan K, Krinsky ML, Strohmeye L, Dominitz JA. The role of endoscopy in the evaluation of suspected choledocolithiasis. GastrointestEndosc. 2010; 71: 1-9.

8. Mayumi T, Okamoto K, Takada T, Strasberg SM, Solomkin JS, Schlossberg D, Pitt HA, Yoshida M, Gomi H, Miura F, Garden OJ, Kiriyama S, Yokoe M, Endo I, Asbun HJ, Iwashita Y, Hibi T, Umezawa A, Suzuki K, Itoi T, Hata J, Han HS, Hwang TL, Dervenis C, Asai K, Mori Y, Huang WS, Belii G, Mukai S, Jagannath P, Chergui D, Kozaka K, Baron TH, de Santibañes E, Higuchi R, Wada K, Gouma DJ, Deziel DJ, Liau KH, Wakabayashi G, Padbury R, Jonas E, Supe AN, Singh H, Gabata T, Chan ACW, Lau WY, Fan ST, Chen MF, Ker CG, Yoon YS, Choi IS, Kim MH, Yoon DS, Kitano S, Inomata M, Hirata K, Inui K, Sumiyama Y, Yamamoto M. Tokyo Guidelines 2018: management bundles for acute cholangitis and cholecystitis. ). J Hepatobiliary Pancreat Sci. 2018; 25: 96-100.

9. Chak A, Cooper GS, Lloyd LE, Hammar PG, Issa $K$, Rosenthal GE. Effectiveness of ERCP in cholangitis: a community-based study. GastrointestEndosc. 2000; 52: 484-9.

10. Khashab MA, Tariq A, Tariq U, et al. Delayed and unsuccessful endoscopic retrograde cholangiopancreatography are associated with worse outcomes in patients with acute 
cholangitis.Clin Gastroenterol Hepatol. 2012 Oct;10(10):1157-61.

11. Hou, LA. Laine L, Motamedi N, Sahakian A, Lane C, Buxbaum J. Optimal timing of endoscopic retrograde cholangiopancreatography in acute cholangitis. J ClinGastroenterol. 2017; 51: 5348.

12. Tabibian JH, Yang JD, Baron TH. Weekend Admission for Acute Cholangitis Does Not Adversely Impact Clinical or Endoscopic Outcomes.Dig Dis Sci. 2016 Jan;61(1):53-61.

13. Keswani RN, Qumseya BJ, O'Dwyer LC, Wani S. Association between endoscopist and center retrograde cholangiopancreatography volume with procedure success and adverse outcomes: a systematic review and meta-analysis. ClinGastroenterolHepatol. 2017; 15: 18661875.

14. ASGE Standards of Practice Committee, Acosta RD, Abraham NS, Chandrasekhara V, Early DS, Eloubeldi MA, Evans JA, Faulx AL, Fisher DA, Fonkalsrud L, Hwang JH, Khashab MA, LIghtdale JR, Muthusamy VR, Pasha SF, Saltzman JR, Shaukat A, Shergill AK, Wang A, Cash BD, DeWitt JM. The management of antithrombotic agents for patients undergoing $\mathrm{Gl}$ endoscopy. GastrointestEndosc. 2016;8 3: 3-16.

15. Veitch AM, Vanbieverliet G, Gershlick AH, Boustiere C, Baglin TP, Smith LA, Radaelli F, Knight E, Grailnek IM, Hassan C, Dumonceau, JM. Endoscopy in patients on antiplatelet or anticoagulant therapy, including direct oral anticoagulants: British Society of Gastroenterology (BSG) and European Society of Gastrointestinal Endoscopy (ESGE) guidelines. Endosc. 2016; https://doi.org/10.1055/s-0042-122686

16. Moss AS, Dimitropoulous G, Lip GYH. Clinical implications, benefits and pitfalls of using and reversing non-vitamin $\mathrm{K}$ antagonist oral anticoagulants. Expert Rev Hematol. 2017 Sep;10(9):833-845

17. Cui PJ, Yao J, Zhao YJ, Han HZ, Yang J. Biliary stenting with or without sphincterotomy for malignant biliary obstruction: a meta-analysis. World J Gastroenterol. 2014; 20: 14033-9.

18. Zhao HC, He L, Zhou DC, Geng ZP, Pan FM. Meta-analysis comparison of endoscopic papillary balloon dilatation and endoscopic sphincteropapillotomy. World J Gastroenterol. 2013; 19: 3883-91

19. Magno-Pereira V, Moutinho-Ribeiro P, Macedo $G$. Demystifying endoscopic retrograde cholangiopancreatography (ERCP) during pregnancy. Eur J ObstetGynecolReprod Biol. 2017; 219:35-39.

20. ASGE Standard of Practice Committee, Shergill AK, Ben-Menachem T, Chandrasekhara V, Chathadi K, Decker GA, Evans JA, Early DS, Fanelli RD, Fisher DA, Foley KQ, Fukami N, Hwang JH, Jain R, Jue TL, Khan KM, Lightdale J, Pasha SF, Sharaf RN, Dominitz JA, Cash BD. GastrointestEndosc. 2012; 76: 18-24.

21. Tomizawa Y, Di Giorgio J, Santos E, McCluskey KM, Gelrud A. Combined interventional radiology followed by endoscopic therapy as a single procedure for patients with failed initial endoscopic biliary access. Dig Dis Sci. 2014; 59: 451-8.

22. Baron TH, Vickers SM. Surgical gastrostomy placement as access for diagnostic and therapeutic ERCP. GastrointestEndosc. 1998; 48: 640-1.

23. Andrew DJ, Johnson SE. Acute suppurative cholangitis, a medical and surgical emergency. A review of ten years experience emphasizing early recognition. Am J Gastroenterol. 1970; 54: 141-54.

24. Chijiiwa K, Kozaki N, Naito T, Kameoka N, Tanaka M. Treatment of choice for 
choledocolithiasis in patients with acute obstructive suppurative cholangitis and liver cirrhosis. Am J Surg. 1995; 170: 356-60.

25. McNabb-Baltar J, Trinh QD, Barkun AN. Biliary drainage method and temporal trends in patients admitted with cholangitis: a national audit. Can J Gastroenterol. 2013; 27: 513-8.

26. Kwon $\mathrm{Cl}$, Gromski MA, Sherman S, Easler JJ, El Haji II, Watkins J, Fogel EL, McHenry L, Lehman GA. Time sequence evaluation of biliary stent occlusion by dissection analysis of retrieved stents. Dig Dis Sci. 2016; 61: 2426-35.
27. Poon RT, Liu CL, Lo CM, Lam CM, Yuen WK, Yeung $C$, Fan ST, Wong J. Management of gallstone cholangitis in the era of laparoscopic cholecystectomy. Arch Surg. 2001; 136: 11-6.

28. Li VK, Yum JL, Yeung YP. Optimal timing of elective laparoscopic cholecystectomy after acute cholangitis and subsequent clearance of choledocolithiasis. Am J Surg. 2010; 200:483-8. 